LIVER

\title{
Dose dependent and divergent effects of superoxide anion on cell death, proliferation, and migration of activated human hepatic stellate cells
}

\author{
E Novo, F Marra, E Zamara, L Valfrè di Bonzo, A Caligiuri, S Cannito, C Antonaci, \\ $S$ Colombatto, M Pinzani, M Parola
}

See end of article for authors' affiliations

Correspondence to: Professor M Parola, Universitò degli Studi di Torino, Dip Medicina e Oncologia Sperimentale, C so Raffaello 30,10125 Torino, Italy; maurizio.parola@ unito.it

Revised version received 2 July 2005 Accepted for publication 16 July 2005 Published online first 24 July 2005

Background and aim: Activated myofibroblast-like cells, originating from hepatic stellate cells (HSC/MFs) or other cellular sources, play a key profibrogenic role in chronic liver diseases (CLDs) that, as suggested by studies in animal models or rat HSC/MFs, may be modulated by reactive oxygen intermediates (ROI). In this study, human $\mathrm{HSC} / \mathrm{MFs}$, exposed to different levels of superoxide anion $\left(\mathrm{O}_{2}^{-{ }^{-}}\right)$and, for comparison, hydrogen peroxide $\left(\mathrm{H}_{2} \mathrm{O}_{2}\right)$, were analysed in terms of cytotoxicity, proliferative response, and migration.

Methods: Cultured human HSC/MFs were exposed to controlled $\mathrm{O}_{2}{ }^{\cdot-}$ generation by hypoxanthine/ xanthine oxidase systems or to a range of $\mathrm{H}_{2} \mathrm{O}_{2}$ concentrations. Induction of cell death, proliferation, and migration were investigated using morphology, molecular biology, and biochemical techniques.

Results: Human $\mathrm{HSC} / \mathrm{MFs}$ were shown to be extremely resistant to induction of cell death by $\mathrm{O}_{2}{ }^{\cdot-}$ and only high rates of $\mathrm{O}_{2}{ }^{--}$generation induced either necrotic or apoptotic cell death. Non-cytotoxic low levels of $\mathrm{O}_{2}{ }^{-}$, able to upregulate procollagen type I expression (but not tissue inhibitor of metalloproteinase 1 and 2), stimulated migration of human HSC/MFs in a Ras/extracellular regulated kinase (ERK) dependent, antioxidant sensitive way, without affecting basal or platelet derived growth factor (PDGF) stimulated cell proliferation. Non-cytotoxic levels of $\mathrm{H}_{2} \mathrm{O}_{2}$ did not affect Ras/ERK or proliferative response. A high rate of $\mathrm{O}_{2}{ }^{--}$generation or elevated levels of $\mathrm{H}_{2} \mathrm{O}_{2}$ induced cytoskeletal alterations, block in motility, and inhibition of PDGF dependent DNA synthesis.

Conclusions: Low non-cytotoxic levels of extracellularly generated $\mathrm{O}_{2}{ }^{--}$may stimulate selected profibrogenic responses in human HSC/MFs without affecting proliferation.

$\mathrm{F}$ ibrotic progression of chronic liver diseases (CLDs) of different aetiology to the end stage of cirrhosis is currently seen as a dynamic and highly integrated cellular response to chronic liver injury. Liver fibrosis is accompanied by perpetuation of liver injury, chronic hepatitis, persisting activation of tissue repair mechanisms, and excess deposition of extracellular matrix (ECM) components. ${ }^{1-9}$ A major active role in fibrogenesis is played by hepatic populations of highly proliferative, fibrogenic, and contractile myofibroblast-like cells (MFs). These cells may have multiple origins as the consequence of a process of activation involving hepatic stellate cells (HSC) and portal (myo)fibroblasts ${ }^{10-12}$ or, as recently suggested, bone marrow derived stem cells. ${ }^{13}$

A major pathogenetic role has been traditionally attributed to MFs originating from activation of HSC (that is, HSC/ MFs), and most of our knowledge concerning the process of activation and related phenotypic responses derives from studies performed on primary cultures of HSC/MFs isolated from either rat or human liver. ${ }^{1346}$ Phenotypic responses of HSC/MFs, that include increased proliferation, increased synthesis of ECM components and proinflammatory mediators, as well as contractility and chemotaxis, are initiated and/or sustained by polypeptide factors, ${ }^{1267}$ ECM changes, ${ }^{5}$ and reactive molecules related to oxidative stress such as reactive oxygen intermediates (ROI) and 4-hydroxynonenal (HNE). ${ }^{12614}$ Along these lines, detection of oxidative stress has been unequivocally reported in either clinical or experimental conditions of CLDs, and ROI and HNE have been proposed as key mediators affecting defined signal transduction pathways, proliferation, and some phenotypic responses of HSC/MFs. ${ }^{14}$ In this regard, superoxide anion $\left(\mathrm{O}_{2}{ }^{--}\right)$appears of particular interest as this ROI is generated "in vivo" by activated inflammatory cells, including Kupffer cells, during CLDs or acute liver injury. ${ }^{14}$ Moreover, data obtained with cultured HSC/MFs exposed to the extracellular generation of $\mathrm{O}_{2}{ }^{--}$suggest that this ROI is able to upregulate procollagen type $\mathrm{I}^{15}$ MCP-1 expression, ${ }^{16}$ and endothelin receptors. ${ }^{17}$ However, in contrast with what has been described for hydrogen peroxide $\left(\mathrm{H}_{2} \mathrm{O}_{2}\right)$, the real impact of this relevant ROI on other major phenotypic responses of HSC/MFs is still largely unexplored. Moreover, a recent study has suggested that exposure of rat HSC/MFs to relatively low levels of $\mathrm{O}_{2}{ }^{--}$may even result in induction of apoptotic cell death. $^{18}$

In this study, fully activated human HSC/MFs, displaying a phenotype of interface myofibroblasts, ${ }^{12}$ were exposed under controlled conditions to extracellularly generated $\mathrm{O}_{2}{ }^{--}$in order to reproduce different "in vivo" conditions (that is,

Abbreviations: CLDs, chronic liver diseases; $\mathrm{ECM}$, extracellular matrix; MFs, myofibroblast-like cells; HSC, hepatic stellate cells; HSC/MFs, activated hepatic stellate cells in myofibroblast-like phenotype; ROI, reactive oxygen intermediates; $\mathrm{O}_{2}{ }^{\circ-}$, superoxide anion; $\mathrm{H}_{2} \mathrm{O}_{2}$, hydrogen peroxide; $\mathrm{HNE}$, 4-hydroxynonenal; TIMP, tissue inhibitor of metalloproteinases; PDGF, platelet derived growth factor; TGF- $\beta 1$, transforming growth factor $\beta 1$; ECL, enhanced chemiluminescence; SFI medium, serum free Iscove's medium; NO, nitric oxide; L-NAME, $\mathrm{N} \omega$-nitro-L-arginine methyl ester; LDH, lactate dehydrogenase; $X / X O$, hypoxanthine/xanthine oxidase system generating superoxide anion; SOD, superoxide dismutase; ERK, extracellular regulated kinase; PI-3 K, phosphatidyl inositol 3-kinase 
persistent activation or burst activation of infiltrating or resident leucocytes and their interaction with HSC/MFs) and to monitor specific profibrogenic responses, such as cell motility and proliferation.

We report that the response of human HSC/MFs strictly depends on the rate of $\mathrm{O}_{2}^{--}$generation, ranging from "profibrogenic" responses (procollagen type I and migration) to induction of cell death in the presence of $\mathrm{O}_{2}{ }^{--}$levels, mimicking chronic inflammation or acute hepatitis, respectively. Profibrogenic responses to $\mathrm{O}_{2}{ }^{--}$did not include proliferation and did not apparently involve $\mathrm{H}_{2} \mathrm{O}_{2}$ generation.

\section{METHODS \\ Materials}

HNE, transforming growth factor $\beta 1$ (TGF- $\beta 1$ ), platelet derived growth factor (PDGF)-BB, genistein, PD-98095, and LY-294002 were from Calbiochem (La Jolla, California, USA). Enhanced chemiluminescence (ECL) reagents and nitrocellulose membranes Hybond-C extra were purchased from Amersham Pharmacia Biotech (Cologno Monzese, Milano, Italy). Polyclonal and monoclonal antibodies were from Santa Cruz Biotech Inc (Santa Cruz, California, USA). Hypoxanthine, xanthine oxidase, and all other reagents were from Sigma Chemical Co. (Sigma Aldrich Spa, Milano, Italy).

\section{Cell isolation and culture}

The use of human material was approved by the ethics committee for research of the University of Florence, where cells were isolated from surgical wedge sections of human liver not suitable for transplantation, as described elsewhere. ${ }^{19}$ Cells were cultured in Iscove's medium supplemented with $20 \%$ fetal bovine serum, subcultured when confluent at a 1:3 split ratio and, unless otherwise stated, used between passages 4 and 7. At these stages of culture, cells show functional and ultrastructural features of fully activated HSC/ MFs with antigen profiles identical to those of "interface" myofibroblasts detected in liver tissue specimens at the border between "active" fibrotic septa and parenchyma. ${ }^{11}{ }^{12}$ In most experiments, confluent HSC/MFs were left for 24 hours in serum free Iscove's (SFI) medium before addition of the stimuli; in experiments designed to evaluate induction of apoptosis or proliferation, cells at $65-70 \%$ confluence were left in SFI medium before addition of stimuli. $^{20}$ Data presented herein were obtained using cells isolated from three different human livers.

Table 1 Estimated mean generation of superoxide anion by the hypoxanthine/xanthine oxidase (X/XO) systems used in this study

\begin{tabular}{|c|c|c|c|}
\hline System & $\begin{array}{l}\text { Hypoxanthine } \\
\text { (mM) }\end{array}$ & $\begin{array}{l}\text { Xanthine } \\
\text { oxidase (mU) }\end{array}$ & $\begin{array}{l}\text { Estimated generation of } \\
\text { superoxide } \\
\text { (nmol } / \mathrm{min} / \mathrm{ml} \text { medium) }\end{array}$ \\
\hline X/XO I & 0.4 & 2 & $0.8-1.2$ \\
\hline X/XO II & 0.2 & 20 & $7-10$ \\
\hline X/XO III & 0.05 & 100 & $25-50$ \\
\hline
\end{tabular}

In order to evaluate estimated mean generation of superoxide anion under controlled conditions (that is, known values of available substrate, enzyme, and enzyme activity, $\mathrm{pH}$, temperature, volume of medium, etc) the methods based on nitroblue of tetrazolium (NBT) reduction ${ }^{21}$ or dichloro-fluorescein (DCF) fluorescence ${ }^{20}$ were used. Kinetics of NBT reduction in culture medium at $37^{\circ} \mathrm{C}$ were found to be essentially linear until substrate consumption in X/XO II and III systems as well as, at least for 45-50 minutes, in the $\mathrm{X} / \mathrm{XO}$ I system also. The DCF method (performed by taking samples of culture medium at desired time points after starting superoxide generation) was then essentially used to establish the time of disappearance of reactive oxygen species dependent DCF fluorescence, in the presence or absence of $100 \mathrm{U}$ of superoxide dismutase, with the $\mathrm{X} / \mathrm{XO}$ I system designed to generate low levels of superoxide over a long period of time.

\section{Superoxide generation}

In preliminary experiments, in order to define standard experimental conditions, generation of $\mathrm{O}_{2}{ }^{--}$in culture medium was ascertained in the presence of different combinations of hypoxanthine/xanthine oxidase (X/XO). Superoxide generation was evaluated as follows: (i) by following the kinetics of nitroblue of tetrazolium reduction ${ }^{21}$; and (ii) by monitoring, for longstanding generation of $\mathrm{O}_{2}{ }^{--}$ (X/XO I system), disappearance of dichloro-fluorescein fluorescence ${ }^{20}$ in culture medium samples obtained at defined time points, in the presence or absence of $100 \mathrm{U}$ of superoxide dismutase (SOD). More details are provided in the footnote to table 1. Control cells were incubated in the absence of xanthine oxidase.

\section{Evaluation of cell death and apoptosis}

Necrotic or apoptotic cell death was evaluated as recently described,$^{20}$ by monitoring release of lactate dehydrogenase (LDH) or 4,6-diamidine-2-phenylindole di-hydrochloride fluorescence staining to detect nuclear DNA and fluorimetric detectable caspase 3-like activity, respectively. A modified clonogenic assay was also performed as previously described. ${ }^{20}$

\section{Western blot and other assays for protein levels}

Cell lysates from HSC/MFs were subjected to sodium dodecyl sulphate-polyacrylamide gel electrophoresis on $10 \%$ or $7.5 \%$ acrylamide gels and blots incubated with the desired primary antibodies, followed by incubation with peroxidase conjugated antimouse or antirabbit immunoglobulins in Tris buffered saline-Tween containing $2 \%(\mathrm{wt} / \mathrm{vol})$ non-fat dry milk, as previously described..$^{22} 23$ Immunoblots were developed with ECL reagents according to the manufacturer's instructions. Procollagen type I levels were analysed by an ELISA method. ${ }^{20}$

\section{RNA extraction and northern blot}

Total RNA from HSC/MFs was isolated as previously described $^{162023}$ and evaluated spectrophotometrically by absorbance at $260 \mathrm{~nm}$. Northern blot analysis of mRNA (tissue inhibitor of metalloproteinases 1 and 2 (TIMP-1, TIMP-2)) was performed according to standard procedures $^{16202223}$ using specific human cDNA probes. ${ }^{24} 25$ To exclude significant sample loading differences, filters were cohybridised with a ${ }^{32} \mathrm{P}$ labelled probe encoding for the ribosomal protein $36 \mathrm{~B} 4 .^{26}$

\section{DNA synthesis and cell migration}

DNA synthesis ${ }^{23}$ as well as migration of human HSC/MFs ${ }^{20} 27$ were evaluated as previously described by monitoring incorporation of $\left[{ }^{3} \mathrm{H}\right]$ thymidine or using the wound healing assay, respectively.

\section{Statistical analysis}

Data in bar graphs represent means (SEM) and means were obtained from average data of at least three independent experiments. Luminograms and morphological images are representative of at least three experiments with similar results. Statistical analysis was performed using the Student's $t$ test or with ANOVA for analysis of variance when appropriate $(\mathrm{p}<0.05$ was considered significant).

\section{RESULTS}

In order to confirm the results of a recent study showing that $\mathrm{O}_{2}{ }^{--}$is able to induce apoptotic cell death in activated rat $\mathrm{HSC}^{18}$ we first evaluated whether exposure of human HSC/ MFs to $\mathrm{O}_{2}{ }^{\cdot-}$ generating systems is followed by induction of cell death. As a first experiment, human HSC/MFs were exposed to a $\mathrm{X} / \mathrm{XO}$ system $(0.4 \mathrm{mM}$ hypoxanthine $/ 2 \mathrm{mU} / \mathrm{ml}$ xanthine oxidase, $\mathrm{X} / \mathrm{XO} \mathrm{I})$, already used in previous 

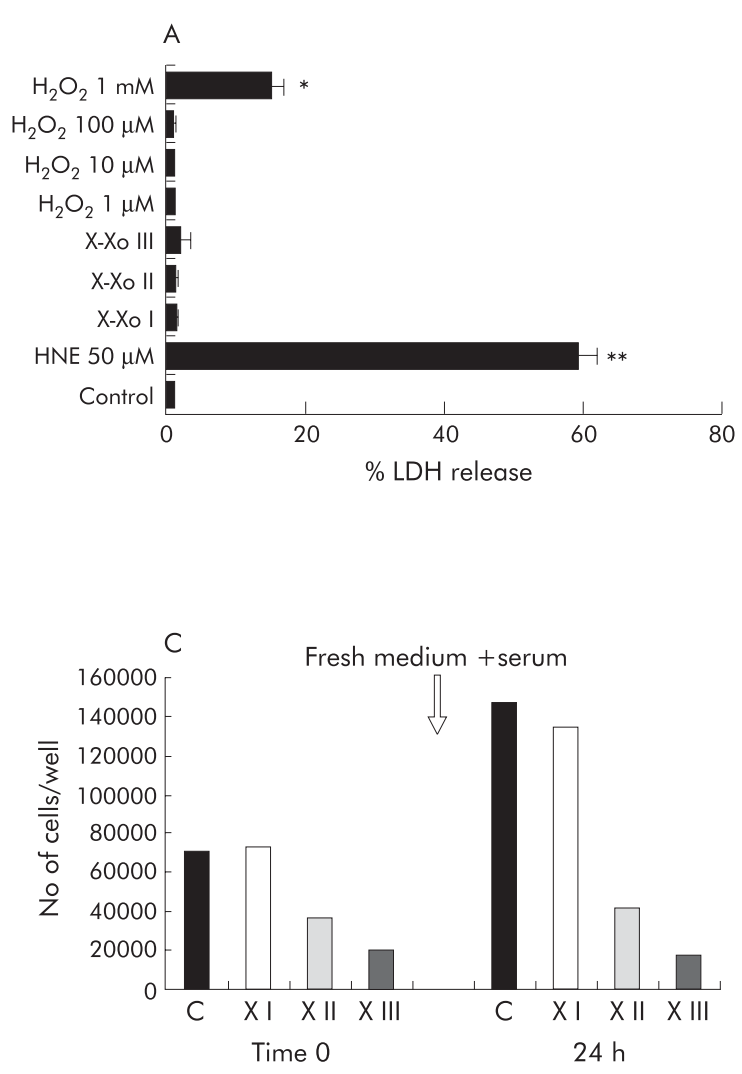
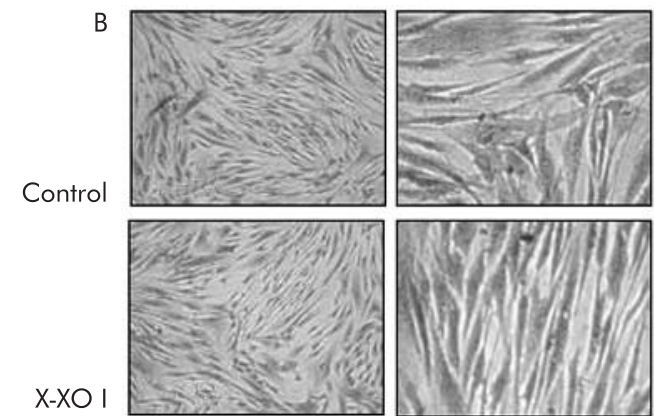

$\mathrm{X}-\mathrm{XO}$ II
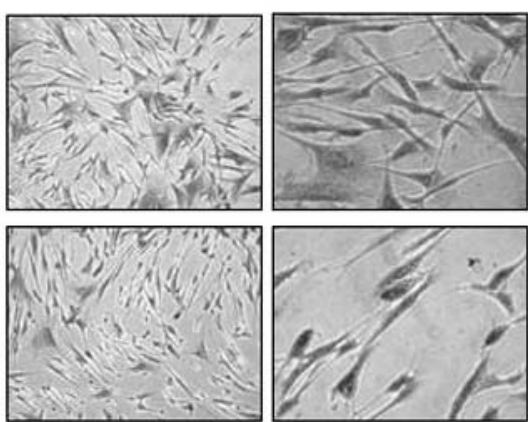

$\mathrm{H}_{2} \mathrm{O}_{2} 100 \mu \mathrm{M}$

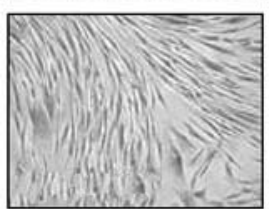

Figure 1 Analysis of the cytotoxic effects of superoxide anion versus cultured human activated hepatic stellate cells in myofibroblast-like phenotype (HSC/MFs). Cytotoxicity of superoxide generated with the three different hypoxanthine/xanthine oxidase (X/XO) systems or, when required for comparative purposes, other agents at the indicated concentrations, were evaluated as follows: (i) by analysing lactate dehydrogenase (LDH) release (A) in culture medium after 24 hours of incubation; experimental data are expressed as per cent LDH release where $100 \%$ represents maximal (that is, total) LDH release from control cells after lysis with Triton X-100; (ii) by analysing morphology (B) at the end of a 24 hour period of incubation of human HSC/MFs exposed to the indicated conditions; (iii) by a modified cholonogenic assay in order to evaluate the ability of cells treated for 24 hours with the indicated X/XO systems in serum free medium, to respond and proliferate to addition of complete medium (new medium plus serum) in terms of adherent cells ( $\mathrm{C}$, bar graph represents the results from a typical experiment, performed three times). $\mathrm{H}_{2} \mathrm{O}_{2}$, hydrogen peroxide; $\mathrm{HNE}$, 4-hydroxynonenal. Data for (A) are mean (SEM) and refer to at least three different experiments. ${ }^{*} p<0.05,{ }^{* \star} p<0.01$ versus control values.

studies. ${ }^{15} 16$ Using this system, resulting in longlasting production of low levels of $\mathrm{O}_{2}^{--}$(see table 1 ), we could not detect any morphological alteration or increase in $\mathrm{LDH}$ release in the medium (necrotic type of cell death) (fig lA, $\mathrm{B})$ or in selected parameters of apoptotic cell death, such as nuclear condensation or caspase 3-like activity (fig 2A, B). By progressively increasing the rate of superoxide generation (see table 1) we observed the following results (illustrated in fig $1 \mathrm{~A}-\mathrm{C}$, fig 2A, 2B):

(i) modest increase in LDH release and some evidence of nuclear condensation (without increase in caspase 3like activity) in the presence of $\mathrm{X} / \mathrm{XO} \mathrm{II}$;

(ii) significant signs of apoptotic cell death (nuclear condensation plus activation of caspase 3-like activity) when cells were exposed to a flash of very high levels of $\mathrm{O}_{2}^{--}$(X/XO III);

(iii) evident morphological changes (fig 1B) in cells exposed to X/XO II and III systems, characterised by more rapid substrate consumption and accelerated generation of higher levels of $\mathrm{O}_{2}{ }^{--}$. Several cells exposed to X/XO II (approximately 25-30\%) showed a condensed and shrunken shape with a neuronal-like appearance; this feature was exacerbated in cells exposed to X/XO III and accompanied by detachment of about $80 \%$ of cells after 24 hours (not shown);

(iv) induction of necrotic or apoptotic type of cell death was seen for human HSC/MFs only in the presence of
$50 \mu \mathrm{M}$ HNE or $100 \mu \mathrm{g} / \mathrm{ml}$ cycloheximide, respectively; these conditions were used as positive controls ${ }^{20}$;

(v) $\mathrm{H}_{2} \mathrm{O}_{2}$, a ROI that may result from conversion of $\mathrm{O}_{2}{ }^{\cdot-}$, induced necrotic cell death, but not apoptosis, only at very high concentrations.

In order to unequivocally check their viability, cells exposed to $\mathrm{X} / \mathrm{XO}$ combinations were also used in a modified clonogenic assay (fig $1 \mathrm{C}$ ). Cells exposed to X/XO I behaved similarly to control cells whereas cells exposed to the other two combinations were either totally (X/XO III) or partially (X/XO II) unable to proliferate after removal of medium and treatment with fresh medium containing serum. As X/XO III exerted very severe cytotoxicity, this combination was not used further in our experiments.

Data concerning absence of any detectable adverse effect of $\mathrm{X} / \mathrm{XO}$ I were confirmed by further experiments. As previously reported, ${ }^{15} \mathrm{X} / \mathrm{XO}$ I upregulated the synthesis of procollagen type I in human HSC/MFs, confirming the profibrogenic potential of low levels of $\mathrm{O}_{2}{ }^{--}$; moreover, the presence of SOD in the medium abolished $\mathrm{X} / \mathrm{XO} \mathrm{I}$ induced synthesis of procollagen type I (fig $3 \mathrm{~A}$ ). However, in the presence of the $\mathrm{X} / \mathrm{XO}$ II system, no significant change in procollagen type I was observed (data not shown). In parallel experiments, no significant effect was exerted by either X/XO I or II system on mRNA synthesis for TIMP-1 or TIMP-2 (fig 3B, 3C).

By performing a wound healing assay we found that exposure of cells to low levels of $\mathrm{O}_{2}^{\cdot-}$ generation (X/XO I) 

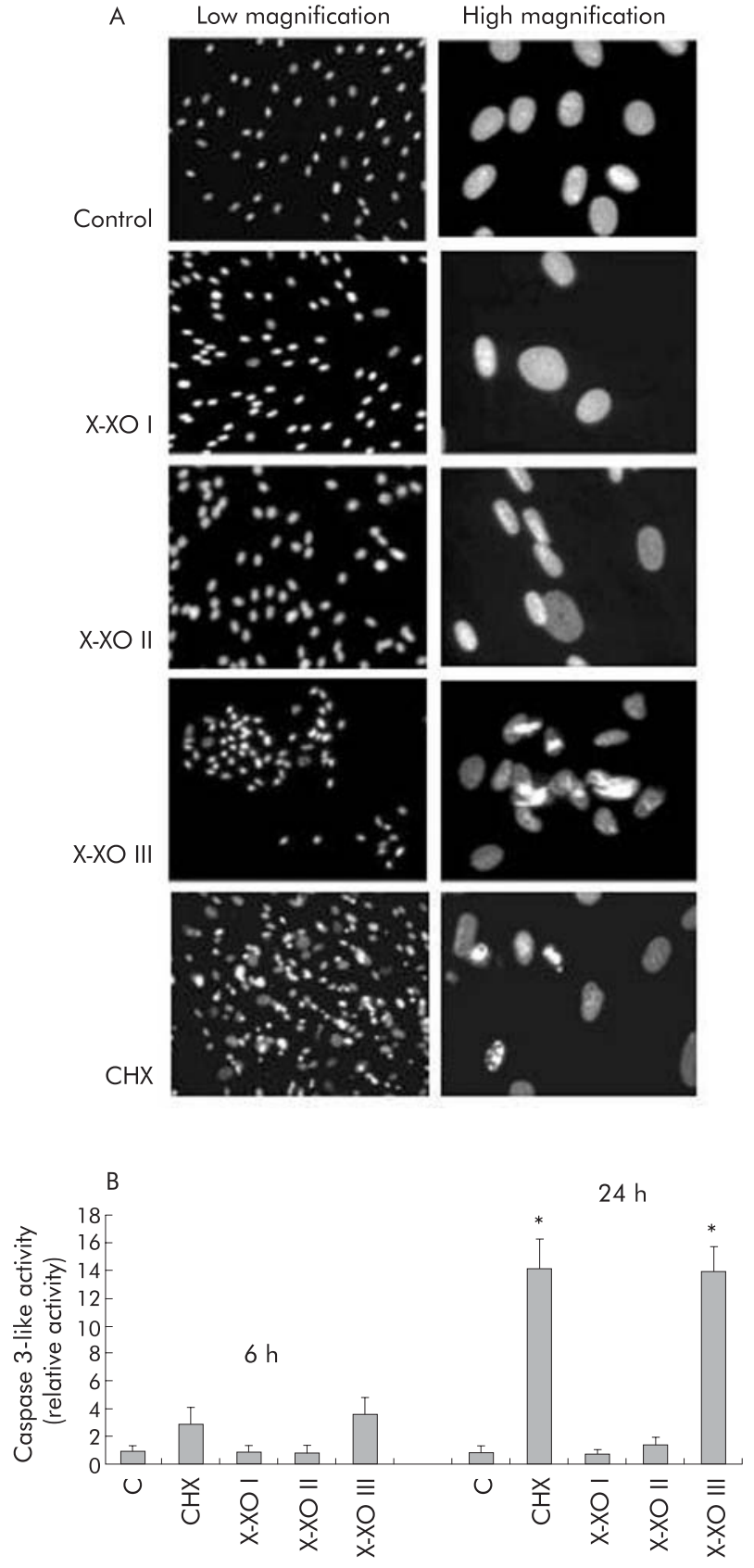

Figure 2 Induction of apoptotic cell death in human activated hepatic stellate cells in myofibroblast-like phenotype (HSC/MFs) exposed to the three different hypoxanthine/xanthine oxidase $(X / X O)$ systems and, for comparison, to cycloheximide (CHX $100 \mu \mathrm{g} / \mathrm{ml})$ as a positive control. Under these experimental conditions, analysis of apoptosis was performed as follows: (i) 4,6-diamidine-2-phenylindole di-hydrochloride (DAPI) fluorescent staining for DNA (A) performed at the end of 24 hours of incubation on either control cells or cells exposed to the different rates of superoxide generation as well as to the $\mathrm{CHX}$ positive control stimulus; (ii) fluorimetric evaluation of caspase 3-like activity (B) in total cell lysates obtained from control and treated cells at the indicated time points. Data represent mean (SEM) of at least three different experiments. ${ }^{*} p<0.01$ versus control values.

resulted in significant stimulation of cell migration, as evaluated by invasion of the artificial wound (fig 4). The entity of this stimulation accounted for approximately 50$60 \%$ of that observed with PDGF-BB, used as a positive control. In contrast, exposure of cells to X/XO II was not only ineffective but also apparently prevented the physiological

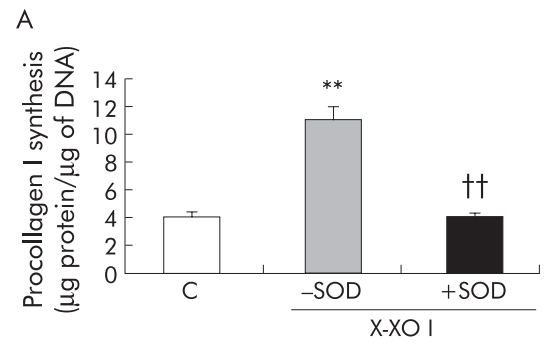

B

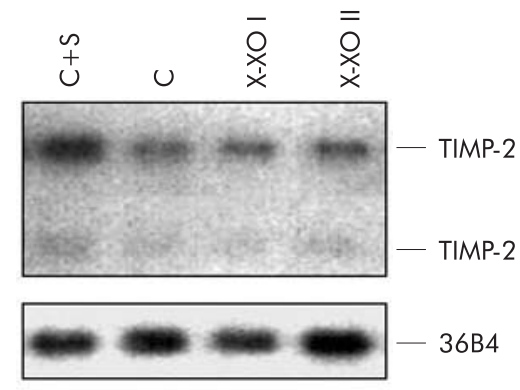

C

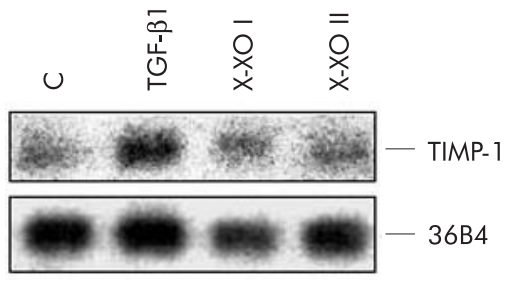

Figure 3 Analysis of the effect of superoxide anion generation versus cultured human activated hepatic stellate cells in myofibroblast-like phenotype (HSC/MFs) in terms of phenotypic responses related to extracellular matrix synthesis and degradation. The following responses were considered: (i) synthesis of procollagen type I (A), as evaluated in culture media of 24 hour serum deprived cells and then either not exposed (control, C) or exposed to the hypoxanthine/xanthine oxidase I $(\mathrm{X} / \mathrm{XO} \mathrm{I})$ system (in the presence or absence of $100 \mathrm{U} / \mathrm{ml}$ of superoxide dismutase (SOD)); data are expressed in terms of $\mu \mathrm{g}$ of protein/ $\mu \mathrm{g}$ of DNA and are means (SEM) $(n=3)\left({ }^{* *} p<0.01 v\right.$ control values;

$\operatorname{ttp}<0.01 v$ values obtained in the presence of $X / X O$ I only); (i) northern blot analysis of mRNA for tissue inhibitor of metalloproteinase (TIMP-2) (B) and TIMP-1 (C) that was performed on RNA isolated from confluent cells incubated for 24 hours in serum free medium and then exposed or not for three hours to the $\mathrm{X} / \mathrm{XO} \mathrm{I}$ and $\mathrm{X} / \mathrm{XO}$ II systems; serum (S) or transforming growth factor $\beta 1$ (TGF- $\beta 110 \mathrm{ng} / \mathrm{ml}$ ) were used as positive controls for TIMP-2 and TIMP-1, respectively. To evaluate sample loading, filters were cohybridised with a probe encoding for the ribosomal protein 36B4.

entry of some cells in the lesion, as is usually observed under control conditions. In other experiments, pharmacological inhibitors of signalling pathways, antioxidants, or other agents were used to better characterise $\mathrm{X} / \mathrm{XO}$ I dependent stimulation of cell motility (fig 5). X/XO I dependent migration of human HSC/MFs was inhibited after pretreatment with: (i) the Ras/extracellular regulated kinase (ERK) pathway inhibitor PD 98095; (ii) the phosphatidyl inositol 3kinase (PI-3 K) pathway inhibitors wortmannin (WT) or LY294002 (LY); (c) SOD or vitamin E. Other agents such as desferrioxamine and actinomycin $\mathrm{D}$ were ineffective on $\mathrm{X} / \mathrm{XO}$ I dependent migration. Exogenous $\mathrm{H}_{2} \mathrm{O}_{2}(1-100 \mu \mathrm{M})$ was ineffective on cell migration.

Data presented in fig 6A indicate that exposure of $\mathrm{HSC} /$ MFs to the $\mathrm{X} / \mathrm{XO} \mathrm{I}$ system was followed by an evident increase in levels of active (that is, phosphorylated) ERK whereas no significant effect was observed for levels of phosphorylated c-Akt. When human cells were exposed to 

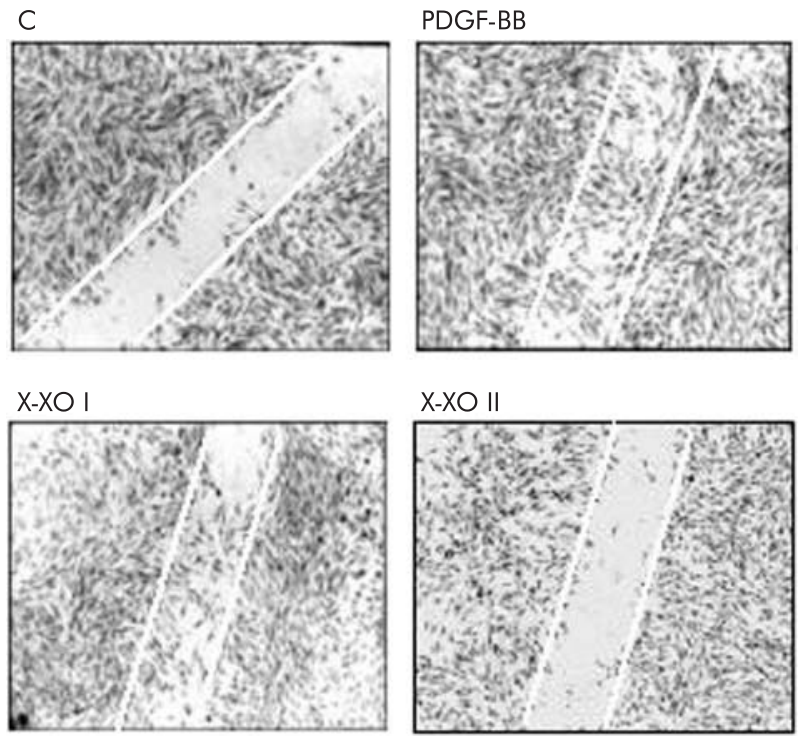

Figure 4 Superoxide anion and migration of human activated hepatic stellate cells in myofibroblast-like phenotype. Wound healing assay was performed on cells seeded on 24 wells coated with collagen type I, grown to confluence in complete medium, and then incubated for 24 hours in serum free medium. A scrape wound was generated in the cell layer to remove a linear area of cells and then cultures were allowed 18 hours to migrate in the absence (control) or presence of the hypoxanthine/xanthine oxidase (X/XO) I and II systems or in the presence of human recombinant platelet derived growth factor (PDGF)$\mathrm{BB}(10 \mathrm{ng} / \mathrm{ml})$ used as a positive control (representative images of at least five experiments in triplicate).

increasing concentrations of $\mathrm{H}_{2} \mathrm{O}_{2}$, no significant change in phosphorylated levels of ERKl/2 was observed (fig 6B).

In order to evaluate whether generation of nitric oxide (NO) may affect X/XO I stimulated migration of human HSC/ MFs, cells were pretreated with the inhibitor of NO synthesis $\mathrm{N} \omega$-nitro-L-arginine methyl ester (L-NAME). L-NAME did not affect X/XO I stimulated migration or activation of ERK (fig 7A, B).

Results observed on Ras/ERK signalling and literature data on rat HSC/MFs prompted us to evaluate whether $\mathrm{O}_{2}{ }^{--}$may be able to affect incorporation of radiolabelled thymidine, used as a sensitive way to monitor DNA synthesis. However, we could not find any significant change in basal incorporation of radiolabelled thymidine (fig 8A) although a trend towards inhibition of basal levels was observed for X/XO II. In contrast, higher levels of superoxide (X/XO II) as well as of $\mathrm{H}_{2} \mathrm{O}_{2}$ clearly inhibited PDGF stimulated DNA synthesis (fig 8A, B), an effect possibly due to ROI mediated inhibition of PDGF-BB dependent downstream signalling, including phosphorylation of ERK1/2, as suggested by the experiments illustrated in fig 9.

\section{DISCUSSION}

Induction of oxidative stress has been unequivocally documented under acute and chronic experimental and clinical conditions of liver injury, and ROI such as $\mathrm{H}_{2} \mathrm{O}_{2}$ and $\mathrm{O}_{2}{ }^{--}$ have been proposed as key profibrogenic and promitogenic stimuli. ${ }^{16}{ }^{14}$ However, this assumption was based on studies limited to rat HSC/MFs and animal models, and no clearcut evidence is currently available in human systems. In addition, we still lack precise analysis of "in vivo" ROI generation during the development of liver injury.

Lores Arnaiz and colleagues ${ }^{28}$ reported that during experimental massive acute liver damage induced by the prooxidant drug acetaminophen, total ROI generation reached
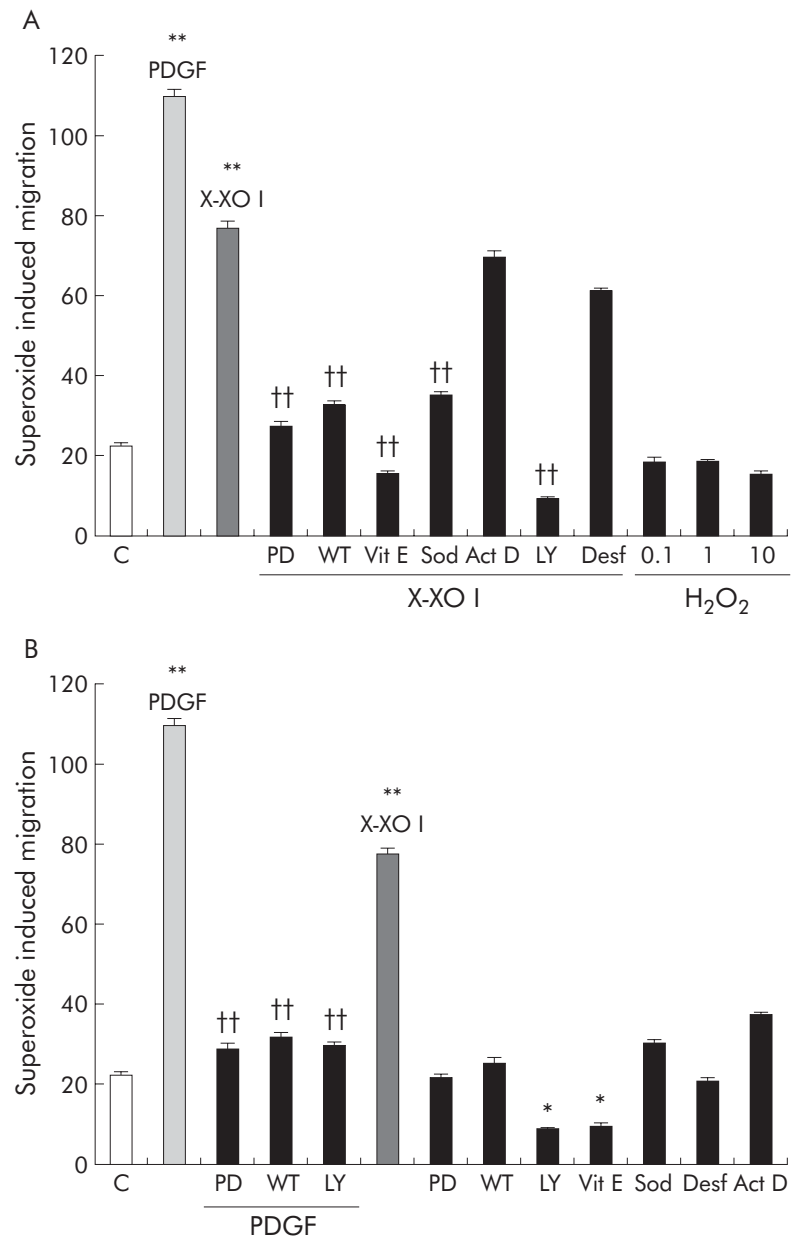

Figure 5 Effects of different agents on superoxide induced migration. Wound healing assay was performed as described in the legend of fig 4. The following basal conditions were used: (i) control cells (untreated); (ii) platelet derived growth factor (PDGF)-BB (10 ng/ml) alone, used as a positive control; (iii) hypoxanthine/xanthine oxidase (X/XO) I; and (iv) hydrogen peroxide $\left(\mathrm{H}_{2} \mathrm{O}_{2} 0.1-10 \mu \mathrm{M}\right)$. When required, control cells or cells exposed to conditions (ii) and (iii) were either pretreated or treated concomitantly with the following agents: $100 \mathrm{U} / \mathrm{ml}$ superoxide dismutase (Sod, concomitant); $100 \mu \mathrm{M}$ vitamin $\mathrm{E}$ (Vit $\mathrm{E}$, one hour preincubation); $100 \mathrm{nM}$ wortmannin (WT, 30 minute preincubation); $30 \mu$ M PD98095 (PD, 30 minute preincubation); LY294002 (LY $10 \mu \mathrm{M}$, 30 minute preincubation); desferrioxamine (Desf $50 \mu \mathrm{M}, 90$ minute preincubation); and actinomycin D (Act D $20 \mathrm{ng} / \mathrm{ml}, 60$ minute preincubation). Data are mean (SEM); $n=5$. ${ }^{*} p<0.05,{ }^{* *} p<0.01$ versus control values; $\dagger+p<0.01$ versus PDGF-BB values.

approximately $250 \mathrm{nM}, 150 \mathrm{nM}$ of which was attributed to $\mathrm{H}_{2} \mathrm{O}_{2}$ generation, indirectly suggesting that superoxide levels should not exceed levels of $100 \mathrm{nM}$ in this model of hyperacute liver damage. On the other hand, data on maximal rate of superoxide generation by activated leucocytes indicate that: (i) activated neutrophils may generate, depending on the stimulus, $10-20 \mathrm{nmol} \mathrm{O}_{2}{ }^{--} / \mathrm{min} / 10^{6}$ cells (value for resting neutrophils being 0.1-0.2) ${ }^{29}$; (ii) Kupffer cells isolated from injured liver may generate up to 10$15 \mathrm{nmol} / 10^{6}$ cells $/ \mathrm{h}^{30}{ }^{31}$; and (iii) superoxide generation, in the perfusate of in vivo perfused /damaged rat livers, may account for $7.0-25.0 \mathrm{nmol} / \mathrm{min} .^{31}{ }^{32}$ On these bases, in the present study, human HSC/MFs were exposed to controlled superoxide generation rates that should be considered as realistic in the attempt to reproduce conditions ranging from mild/moderate inflammation $(0.8-1.2 \mathrm{nmol} / \mathrm{min} / \mathrm{ml})$ to sustained inflammatory response/acute hepatitis (up to 25$50 \mathrm{nmol} / \mathrm{min} / \mathrm{ml}$ ). 

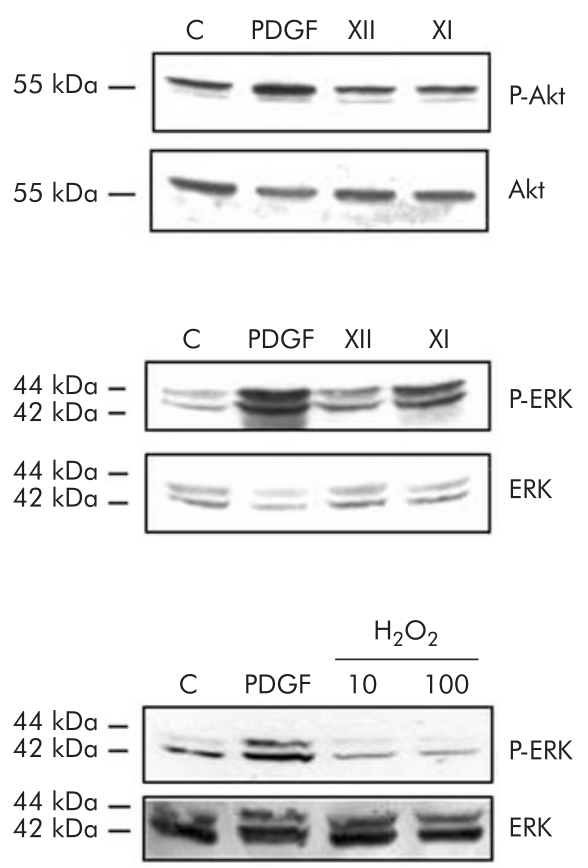

Figure 6 Superoxide generation and critical signalling pathways. Activated hepatic stellate cells in myofibroblast-like phenotype (HSC) MFs) confluent cells were left for 24 hours in serum free medium and then incubated for 15 minutes with the two superoxide anion generating systems (hypoxanthine/xanthine oxidase (X/XO) I and II) as well as with 10 or $100 \mu M$ hydrogen peroxide $\left(\mathrm{H}_{2} \mathrm{O}_{2}\right)$ or platelet derived growth factor (PDGF)-BB (10 ng/ml, used as a positive control). Cell lysates, processed as described in the methods section, were used in western blot analysis in order to detect the state of phosphorylation of extracellular regulated kinase (ERK)1/2 (p42 and p44) and c-Akt by using specific antibodies directed against the phosphorylated form of ERK and c-Akt. Sample loading was evaluated by reblotting membranes with antibodies raised against ERK and c-Akt, respectively. Representative blots are shown of at least three different experiments.

The first important observation is that low and noncytotoxic levels of $\mathrm{O}_{2}{ }^{--}$(estimated generation of approximately $1 \mathrm{nmol} / \mathrm{min} / \mathrm{ml}$ ) not only stimulate procollagen type I expression, in agreement with previous results, ${ }^{15}$ but also differently affect two peculiar profibrogenic responses of human HSC/MFs, such as migration and proliferation.

Superoxide stimulated migration seems strictly dependent on activation of Ras/ERK signalling, as $\mathrm{O}_{2}{ }^{--}$generation is followed by a rapid increase in the phosphorylated form of ERKI/2 and is virtually abolished by the specific MEKl inhibitor PD98095. However, although both wortmannin and LY294002 were able to also significantly prevent PDGF-BB as well as $\mathrm{O}_{2}{ }^{--}$stimulated migration, the two inhibitors also abolished basal migration of control cells and no significant change in phosphorylated c-Akt was observed. This suggests that activation of the PI-3 K pathway, known to contribute to HSC/MFs chemotaxis, may have a less relevant role here than the Ras/ERK pathway. On the other hand, it should be noted that both wortmannin and LY294002 have been reported to inhibit ERK activation by $40 \%^{33}$ and, more importantly, that activation of the PI3-K pathway is much more relevant for mediating mitogenic stimuli in human HSC/MFs. ${ }^{6}$ Moreover, the common observation that PI-3K is more relevant for proliferation than for migration of human HSC/ MFs may help explain why superoxide, able to activate Ras/ ERK but not the PI-3K pathway, does not stimulate DNA synthesis.

Superoxide stimulated migration was also prevented by pretreatment with the antioxidant vitamin $\mathrm{E}$ or when cells

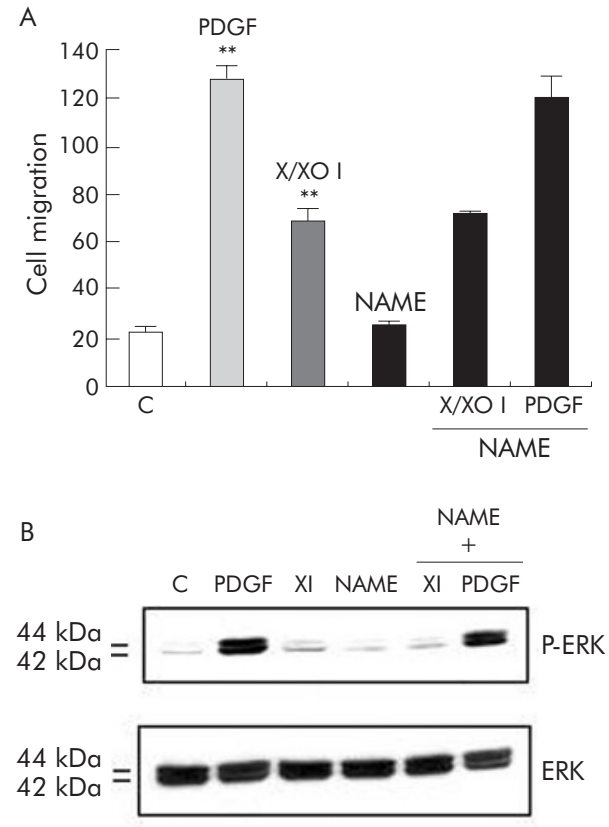

Figure 7 Superoxide stimulated migration did not involve nitric oxide (NO) synthesis. Activated hepatic stellate cells in myofibroblast-like phenotype (HSC/MFs) were evaluated for either cell migration in a wound healing assay (A) or for phosphorylation of extracellular regulated kinase (ERK) (B), exactly as described in the legend of figs 4 and 6 , respectively, with the exception that in order to analyse the involvement of NO synthesis in the hypoxanthine/xanthine oxidase (X) $\mathrm{XO})$ dependent migration, cultured $\mathrm{HSC} / \mathrm{MFs}$ were also pretreated with $\mathrm{N} \omega$-nitro-L-arginine methyl ester (L-NAME $2 \mathrm{mM}$ ) for 16 hours before addition of the pro-oxidant system. Cells were also exposed to platelet derived growth factor (PDGF)-BB alone $(10 \mathrm{ng} / \mathrm{ml}$, positive control, or to L-NAME alone (2 $\mathrm{mM}$, negative control). Data in (A) are mean (SEM) $(n=3) .{ }^{* *} p<0.01$ versus control values. For western blot analysis, sample loading was evaluated by reblotting membranes with antibodies raised against ERK and c-Akt, respectively. Representative blots are shown of at least three different experiments.

were maintained in SOD containing medium, indicating the oxidative dependent nature of migration and a role for superoxide itself. In addition, desferrioxamine pretreatment was ineffective, suggesting that involvement of traces of iron should not be relevant in mediating superoxide effects. According to the latter finding and to the preventive effect of SOD (that is, the enzyme enhancing dismutation of $\mathrm{O}_{2}{ }^{--}$to $\left.\mathrm{H}_{2} \mathrm{O}_{2}\right), \mathrm{H}_{2} \mathrm{O}_{2}$ was unable to affect migration of HSC/MFs and had no effect on either the Ras/ERK or PI 3-K pathway or DNA synthesis. Further manipulation of the experimental design in the wound healing assay (migration evaluated after 18 hours from exposure to the desired stimulus) also apparently excluded involvement of NO synthesis as well as at least an early contribution of an autocrine, superoxide induced regulation of peptide chemotactic factors, such as monocyte chemoattractant protein $1,{ }^{16}$ as indicated by lack of significant effects observed with actinomycin D.

Another major finding from the present study was that $\mathrm{O}_{2}{ }^{\cdot-}$ could not stimulate DNA synthesis in human HSC/MFs when used at profibrogenic and non-cytotoxic levels. In addition, $\mathrm{O}_{2}{ }^{--}$exerted an inhibitory effect on either basal or PDGF dependent DNA synthesis when experimental conditions were set to generate higher levels of superoxide. This feature was fully reproduced in analogous experiments in which human cells were exposed, for comparison, to a range of $\mathrm{H}_{2} \mathrm{O}_{2}$ concentrations. This finding is clearly not in agreement with various reports that, by using different experimental strategies, indicated a link between ROI generation and proliferation of rat $\mathrm{HSC} / \mathrm{MFs},{ }^{35-40}$ through a 

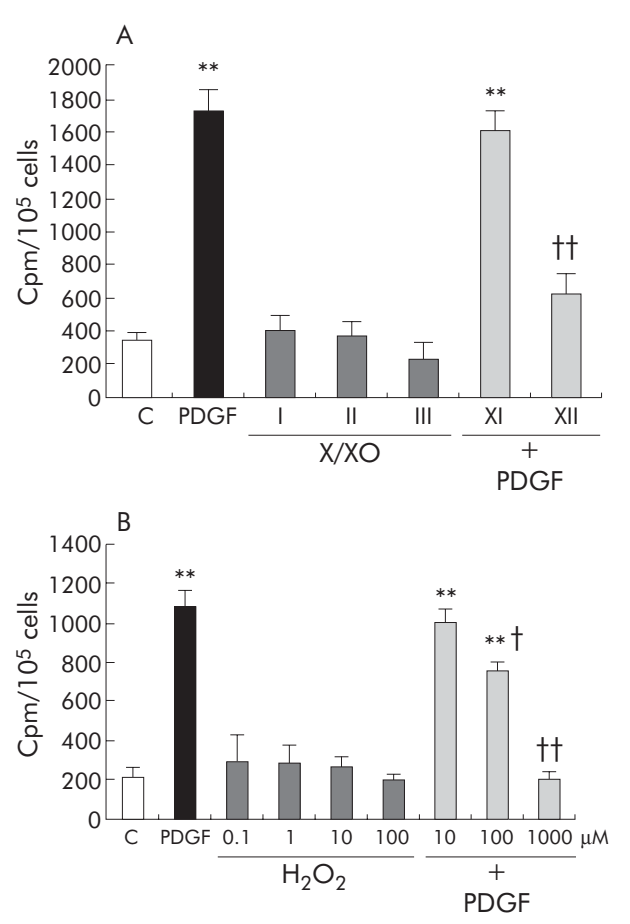

Figure 8 Action of superoxide anion and hydrogen peroxide $\left(\mathrm{H}_{2} \mathrm{O}_{2}\right)$ on DNA synthesis. DNA synthesis was evaluated as incorporation of $\left[{ }^{3} \mathrm{H}\right]$ thymidine in $65-70 \%$ confluent cells, incubated for 24 hours in serum free medium, and then exposed to the desired experimental conditions. (A) Human activated hepatic stellate cells in myofibroblastlike phenotype (HSC/MFs) were exposed or not (control, C) to (i) the hypoxanthine/xanthine oxidase $(X / X O)$ systems, (ii) platelet derived growth factor (PDGF)-BB $(10 \mathrm{ng} / \mathrm{ml})$, used as a positive mitogenic stimulus, or (iii) X/XO I and II systems for one hour and then to PDGF-BB. (B) Human HSC/MFs were exposed or not (control) to (i) indicated concentrations of $\mathrm{H}_{2} \mathrm{O}_{2}$, (ii) PDGF-BB $(10 \mathrm{ng} / \mathrm{ml})$, used as a positive mitogenic stimulus, or (iii) 10,100 , and $1000 \mu \mathrm{M} \mathrm{H}_{2} \mathrm{O}_{2}$ for one hour and then to PDGF-BB. Data are presented as $\mathrm{cpm} / 10^{5}$ cells/well and are means $(S E M)(n=6) .{ }^{* *} p<0.01$ versus control values; $\dagger p<0.05$, t†p $<0.01$ versus values obtained in the presence of PDGF-BB alone.

pathway involving redox modulation of cysteine residues in Raf-1, MEK, and ERK. ${ }^{41}$ In our hands, $\mathrm{H}_{2} \mathrm{O}_{2}$ was not even able to activate the Ras/ERK pathway and, accordingly, it was ineffective not only on DNA synthesis but also on migration. However, it should be noted that the literature also indicates that activated HSC have unusually high levels of catalase activity, being able to metabolise $\mathrm{H}_{2} \mathrm{O}_{2}$ with a very high efficiency, ${ }^{42}{ }^{43}$ and that upregulation of collagen type I in HSC overexpressing CYP2El has been reported to be prevented by Mn-SOD, ${ }^{39}$ suggesting a major role for superoxide rather than $\mathrm{H}_{2} \mathrm{O}_{2}$. Alternatively, lack of effect of $\mathrm{H}_{2} \mathrm{O}_{2}$ may depend on the type of cell used (that is, human $v$ rat cells), as suggested by other findings: (i) human HSC/MFs survive to levels of $\mathrm{O}_{2}{ }^{-{ }^{-}}$ that have been recently described to induce significant caspase dependent apoptosis in rat cells ${ }^{18}$; (ii) human HSC/ MFs, but not rat cells, significantly respond to HNE in a profibrogenic way ${ }^{14} 20$; and (iii) human HSC/MFs, but again not rat cells, either survive several different proapoptotic stimuli, including those efficient on rat HSC/MFs, ${ }^{144}$ as well as $\mathrm{HNE}$ or $\mathrm{H}_{2} \mathrm{O}_{2}$, or require unusually high levels of cytotoxic agents to undergo necrotic or apoptotic cell death, ${ }^{20} 4546$ (and this study and Novo and colleagues, unpublished results) possibly as a consequence of an activation dependent change of equilibrium between pro- and antiapoptotic proteins in activated human HSC/MFs, with a potential major role for $\mathrm{Bcl} 2$ overexpression $^{45-47}$ (Novo and colleagues, unpublished results). Moreover, human HSC/MFs survival to ROI exposure
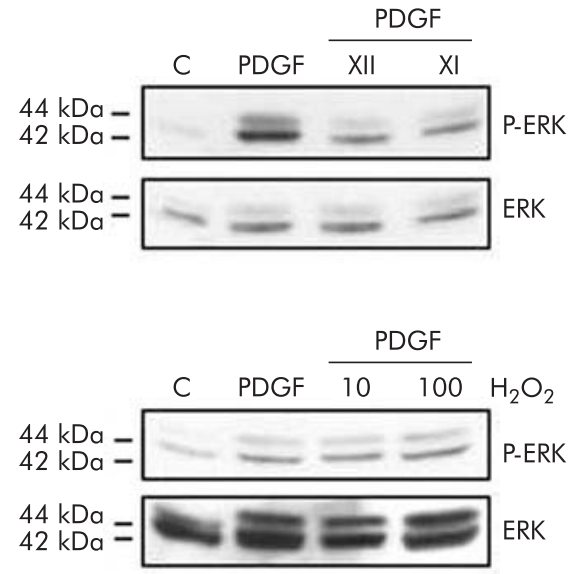

Figure 9 High levels of superoxide generation or hydrogen peroxide $\left(\mathrm{H}_{2} \mathrm{O}_{2}\right)$ inhibit platelet derived growth factor (PDGF)-BB dependent phosphorylation of extracellular regulated kinase (ERK)1/2. Human activated hepatic stellate cells in myofibroblast-like phenotype (HSC) MFs) at 65-70\% confluence, deprived of serum for 24 hours, were incubated with: (i) PDGF vehicle (control, C) for 15 minutes; (ii) PDGF-BB alone $(10 \mathrm{ng} / \mathrm{ml})$, as a positive control, for 15 minutes; (iii) hypoxanthine/xanthine oxidase (X/XO) I and II systems; or (iv) 10 and $100 \mu \mathrm{M} \mathrm{H}_{2} \mathrm{O}_{2}$ for one hour and then exposed to PDGF-BB alone $(10 \mathrm{ng} / \mathrm{ml})$ for an additional 15 minutes. Total lysates were obtained from all conditions at the end of a 15 minute incubation period from either PDGF-BB or vehicle treatment. Cell lysates, processed as described in the methods section, were used in western blot analysis in order to detect the state of phosphorylation of ERK1/2 (p42 and p44) using specific antibodies directed against the phosphorylated form of ERK. Sample loading was evaluated by reblotting membranes with antibodies raised against unphosphorylated ERK. Representative blots are shown of at least three different experiments.

may also involve a ROI dependent upregulation of nuclear factor $\mathrm{\kappa B}$; this redox modulated transcription factor may also elicit survival signalling and indeed preliminary data indicated that human HSC/MFs can easily survive even to high levels of tumour necrosis factor $\alpha^{45} 46$

In conclusion, this study suggests that human HSC/MFs, displaying an antigenic profile identical to that of interface myofibroblast in human fibrotic and cirrhotic livers, ${ }^{11}{ }^{12}$ respond to low non-cytotoxic levels of superoxide, equivalent to those easily detectable in chronic liver diseases, by affecting ECM synthesis or by stimulating in a Ras/ERK dependent manner migration of these key profibrogenic cells. This feature may be relevant in conditions of chronic inflammation that usually accompany chronic liver diseases, also on the basis of the recently revisited major profibrogenic role of macrophages. ${ }^{248}$ Moreover, we have reported for the first time that proliferation of human HSC/MFs, differently from that reported or suggested for rat cells, is not stimulated by ROI used at profibrogenic and non-cytotoxic concentrations. Finally, human HSC/MFs undergo block of proliferative responses as well as necrotic or apoptotic cell death when exposed to higher levels of ROI that may mimic conditions of acute liver injury (that is, acute hepatitis). In particular, high levels of ROI inhibit PDGF-BB dependent proliferation, likely by inhibiting relevant downstream steps of signalling, similar to what has already been reported in human HSC/MFs for another oxidative stress mediator, such as HNE. ${ }^{23}$ Along these lines, one may speculate that after an acute liver injury, time dependent changes in hepatic levels of ROI, like superoxide, may differently affect the response of HSC during wound healing.

Taken together, the results of the present study further refine the concept of the direct profibrogenic effect of ROI (that is, induction of fibrillar ECM synthesis) in the absence 
of significant proliferation of ECM producing cells. This condition likely represents the first profibrogenic step in clinical settings characterised by excessive oxidative stress such as alcoholic and non-alcoholic steatohepatitis.

\section{ACKNOWLEDGEMENTS}

Supported by grants from MIUR (protocols MM06315722 and RBAU01SHY4), Regione Piemonte (Torino, Italy), and Italian Liver Foundation (Florence, Italy).

\section{Authors' affiliations}

E Novo, E Zamara, L Valfrè di Bonzo, S Cannito, C Antonaci, S Colombatto, M Parola, Dip Medicina e Oncologia Sperimentale, University of Torino, Torino, Italy

F Marra, A Caligiuri, M Pinzani, Dip Medicina Interna-Centro di Ricerca, Trasferimento e Alta Formazione "DENOTHE", University of Florence, Florence, Italy

Conflict of interest: None declared.

\section{REFERENCES}

1 Friedman SL. Liver fibrosis: from bench to bedside. $J$ Hepatol 2003:38:S38-53.

2 Friedman SL. Mac the knife? Macrophages - the double-edged sword of hepatic fibrosis. J Clin Invest 2005;115:29-32.

3 Pinzani M, Gentilini P. Biology of hepatic stellate cells and their possible relevance in the pathogenesis of portal hypertension and cirrhosis. Semin Liver Dis 1999:19:397-410.

4 Benyon RC, Arthur MJP. Extracellular matrix degradation and the role of hepatic stellate cells. Sem Liver Dis 2001;21:373-85.

5 Schuppan D, Ruehl M, Somasundran R, et al. Matrix as a modulator of hepatic fibrogenesis. Semin Liver Dis 2001:21:351-72.

6 Pinzani M, Marra F. Cytokine receptors and signaling in hepatic stellate cells. Semin Liver Dis 2001;21:397-416.

7 Pinzani M. PDGF and signal transduction in hepatic stellate cells. Front Biosci 2002;7:397-416.

8 Bedossa P, Paradis V. Liver extracellular matrix in health and disease. J Pathol 2003;200:504-15.

9 Shao R, Rockey DC. Effects of endothelins on hepatic stellate cell synthesis of endothelin-1 during hepatic wound healing. J Cell Physiol 2002;191:342-50.

10 Ramadori G, Saile B. Mesenchymal cells in the liver-one cell type or two? Liver 2002;22:283-94.

11 Cassiman D, Roskams T. Beauty is in the eye of the beholder: emerging concepts and piffalls in hepatic stellate cell research. J Hepatol 2002:37:527-35.

12 Cassiman D, Libbrecht L, Desmet V, et al. Hepatic stellate cell/myofibroblast subpopulations in fibrotic human and rat livers. J Hepatol 2002;36:200-9.

13 Baba S, Fuiii H, Hirose T, et al. Commitment of bone marrow cells to hepatic stellate cells in mouse. J Hepatol 2004;40:255-60.

14 Parola $M$, Robino $G$. Oxidative stress-related molecules and liver fibrosis. $J$ Hepatol 2001;35:297-306.

15 Casini A, Ceni E, Salzano R, et al. Neutrophil-derived superoxide anion induces lipid peroxidation and stimulates collagen synthesis in human hepatic stellate cells: role of nitric oxide. Hepatology 1997; 25:361-7.

16 Marra F, Defranco R, Grappone C, et al. Expression of monocyte chemotactic protein-1 precedes monocyte recruitment in a rat model of acute liver injury, and is modulated by vitamin E. J Invest Med 1999;47:66-75.

17 Gabriel A, Kuddus RH, Rao AS, et al. Superoxide-induced changes in endothelin (ET) receptors in hepatic stellate cells. J Hepatol 1998:29:614-27.

18 Thirunavukkarasu C, Watkins S, Harvey SAK, et al. Superoxide-induced apoptosis of activated rat hepatic stellate cells. J Hepatol 2004;41:567-75.

19 Casini A, Pinzani M, Milani S, et al. Regulation of extracellular matrix synthesis by transforming growth factor $\beta 1$ in human fat-storing cells. Gastroenterology 1993;10:245-53.

20 Zamara E, Novo E, Marra F, et al. 4-Hydroxynonenal as a selective profibrogenic stimulus for activated human hepatic stellate cells. J Hepatol 2004; $40: 60-8$

21 Aruoma OI, Halliwell B, Hoey BM, et al. The antioxidant action of taurine, hypotaurine and their metabolic precursors. Biochem J 1988;256:251-5.
22 Parola $M$, Robino G, Marra F, et al. HNE interacts directly with JNK isoforms in human hepatic stellate cells. J Clin Invest 1998;102:1942-50.

23 Robino G, Parola M, Marra F, et al. Interaction between 4-hydroxy-2,3alkenals and the platelet-derived growth factor-beta receptor. Reduced tyrosine phosphorylation and downstream signaling in hepatic stellate cells. J Biol Chem 2000;275:40561-7.

24 Milani S, Herbst $H$, Schuppan D, et al. Differential expression of matrix metalloproteinase- 1 and -2 genes in normal and fibrotic human liver. Am J Pathol 1994; 144:528-37.

25 Herbst $\mathrm{H}$, Wege T, Milani S, et al. Tissue inhibitor of metalloproteinase 1- and 2- RNA expression in rat and human liver fibrosis. Am J Pathol 1997; 150:1647-59

26 Bassett $P$, Bellocq JP, Wolf $C$, et al. A novel metalloproteinase gene specifically expressed in stromal cells of breast carcinoma. Nature 1990:348:699-704.

27 Mazzocca A, Carloni V, Sciammetta S, et al. Expression of transmembrane 4 superfamily (TM4SF) proteins and their role in hepatic stellate cell motility and wound healing migration. J Hepatol 2002;37:322-30.

28 Lores Arnaiz S, Llesuy S, Cutrin JC, et al. Oxidative stress by acute acetaminophen administration in mouse liver. Free Radic Biol Med 1995; 19:303-10

29 Babior B. NADPH oxidase: an update. Blood 1999;93:1464-76.

30 Teufelhofer O, Parzefall W, Kainzbauer E, et al. Superoxide generation from kupffer cells contribute to hepatocarcinogenesis: studies on NADPH oxidase knockout mice. Carcinogenesis 2005;26:319-29.

31 Bautista AP, Spitzer JJ. Superoxide anion generation by in situ perfused rat liver: effect of in vivo endotoxin. Am J Physiol 1990;259:G907-12.

32 Bautista AP, Schuler A, Spolarics Z, et al. Tumour necrosis factor-alfa stimulate superoxide anion generation by perfused rat liver and Kupffer cells. Am J Physiol 1991;261:G891-5.

33 Marra F, Pinzani M. DeFranco R, et al. Involvement of phosphatidylinositol-3 kinase in the activation of extracellular signal-regulated kinase by PDGF in hepatic stellate cells. FEBS Lett 1995;376:141-5.

34 Gentilini A, Marra F, Gentilini P, et al. Phosphatidylinositol-3 kinase and extracellular signal-regulated kinase mediate the chemotactic and mitogenic effects of insulin-like growth factor-l in human hepatic stellate cells. J Hepatol 2000;32:227-34

35 Buck M, Kim DJ, Houglum K, et al. C-Myb modulates transcription of the $\alpha$ smooth muscle actin gene in activated hepatic stellate cells. Am J Physiol 2000;278:G321-8.

36 Nieto N, Friedman SL, Cederbaum Al. Stimulation and proliferation of primary rat hepatic stellate cells by cytochrome P450 2E1-derived reactive oxygen species. Hepatology 2002;35:62-73.

37 Kawada N, Seki S, Inove M, et al. Effect of antioxidants, resveratrol, quercetin and $\mathrm{N}$-acetylcysteine, on the functions of cultured rat hepatic stellate cells and Kupffer cells. Hepatology 1998;27:1265-74.

38 Reeves HL, Dach CL, Peak M, et al. Stress-activated protein kinases in the activation of rat hepatic stellate cells in culture. J Hepatol 2000;32:465-72.

39 Svegliati-Baroni G, Di Sario A, Casini A, et al. The $\mathrm{Na}+/ \mathrm{H}+$ exchanger modulates the fibrogenic effect of oxidative stress in rat hepatic stellatecells. J Hepatol, 30:868-75.

40 Benedetti A, Di Sario A, Casini A, et al. Inhibition of the $\mathrm{Na}^{+} / \mathrm{H}^{+}$exchanger reduces rat hepatic stellate cell activity and liver fibrosis: an in vitro and in vivo study. Gastroenterology 2001;120:545-56.

$41 \mathrm{Kim}$ YK, Rhim TY, Choi I, et al. N-Acetylcysteine induces cell cycle arrest in hepatic stellate cells through its reducing activity. J Biol Chem 2001; 276:40591-8

42 De Bleser PJ, Xu G, Rombouts K, et al. Glutathione levels discriminate between oxidative stress and transforming growth factor $\beta$ signaling in activated rat hepatic stellate cells. J Biol Chem 1999;274:33881-7.

43 Nieto N, Friedman SL, Greenwel P, et al. CYP2E1-mediated oxidative stres induces collagen type I expression in activated rat stellate cells. Hepatology 1999;30:987-96.

44 Iredale JP. Hepatic stellate cell behaviour during resolution of liver injury Semin Liver Dis 2001;21:427-36.

45 Zamara E, Bonacchi A, Novo A, et al. Activated human hepatic stellate cells are resistant to classic pro-apoptotic stimuli. J Hepatol 2003;38(suppl 2):P21.

46 Novo E, Marra F, Zamara E, et al. High levels of bcl-2, c-akt and trk-a in activated human hepatic stellate cells: possible mechanisms for survival to apoptosis induction. J Hepatol 2004;40(suppl 1):98.

47 Schnabl B, Purbeck CA, Choi YH, et al. Replicative senescence of activated human hepatic stellate cells is accompanied by a pronounced inflammatory but less fibrogenic phenotype. Hepatology 2003;37:653-64.

48 Duffield JS, Forbes SJ, Constadinou CM, et al. Selective depletion of macrophages reveal distinct, opposing roles during liver injury and repair. J Clin Invest 2005;115:56-65. 